\title{
Ecofriendly synthesis of silver nanoparticles from leaves extract of Phyllanthus niruri (L.) and their antibacterial properties
}

\author{
Amalorpavamary G, Dineshkumar G, Jayaseelan K \\ P.G. and Research Department of Zoology and Biotechnology, A.V.V.M. Sri Pushpam College, Poondi-613 503, Thanjavur District, Tamil Nadu, \\ India.
}

\begin{abstract}
In recent times, plant-mediated synthesis of nanoparticles has garnered wide interest owing to its inherent features such as rapidity, simplicity, eco-friendliness and cheaper costs. For the first time, silver nanoparticles were successfully synthesized using Phyllanthus niruri leaf extract in the current investigation. The silver nanoparticles were characterized by UV-Vis spectrophotometer and the characteristic surface plasmon resonance peak was identified to be $423 \mathrm{~nm}$. The morphology of the silver nanoparticles was characterized by scanning electron microscopy (SEM). The size of the silver nanoparticles was found to be $10-50 \mathrm{~nm}$, with an average size $15 \mathrm{~nm}$. FTIR analysis was done to identify the functional groups responsible for the synthesis of the AgNPs. The antibacterial potential of synthesized AgNPs was compared with that of aqueous extracts of P.niruri by well diffusion method. The AgNPs at $50 \mu$ l concentration significantly inhibited bacterial growth against A.hydrophila $(16 \pm 0.09 \mathrm{~mm})$. Thus AgNPs showed broad spectrum antibacterial activity at lower concentration and may be a good alternative therapeutic approach in future.
\end{abstract}

Keywords: Phyllanthus niruri, AgNps, Aeromonas hydrophila, Antibacterial Activity.

Article Info: Received 02 Jan 2019; Review Completed 29 Jan 2019; Accepted 02 Feb 2019; Available online 15 Feb 2019

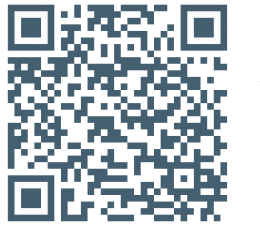

\section{Cite this article as:}

Amalorpavamary G, Dineshkumar G, Jayaseelan K Ecofriendly synthesis of silver nanoparticles from leaves extract of Phyllanthus niruri (L.) and their antibacterial properties, Journal of Drug Delivery and Therapeutics. 2019; 9(1-s):196-200 DOI: http://dx.doi.org/10.22270/jddt.v9i1-s.2304

\section{*Address for Correspondence:}

Dr. K. Jayaseelan, Assistant Professor, P.G. and Research Department of Zoology and Biotechnology, A.V.V.M. Sri Pushpam College, Poondi-613 503, Thanjavur District, Tamil Nadu, India.

\section{INTRODUCTION}

Green nanotechnology is an interdisciplinary field for the production of functional nanoparticles of gold, silver, zinc, etc, [1]. Silver nanoparticles (AgNPs) possessed many noteworthy biological roles in the fields like therapeutics (antimicrobial, anticancer, antiparasitic, antidiabetic and antioxidant activities) [2]. Over the past few decades, the use of plants with different applications in medicine and industry has been growing increasingly in the world. In recent years, many environmentally friendly methods have been employed in the synthesis of nanoparticles [4]. The biological methods for AgNPs synthesis using bacteria, fungi, proteins, polypeptides, nucleic acids and plant extracts are simple, nontoxic, affordable and environmentally friendly. These biological methods can be used to generate nanoparticles with acceptable size and morphology [5].

Phyllanthus niruri Linn. Belongs to Euphorbiaceae family and it is a small herb having wide range of medicinal properties, and it is used widely across the world. In Indian ayurvedic and Unani system it is used for Jaundice, ulcers, skin diseases, diabetes, chest pain and urinary complications. Its taste is bitter and acts as astringent and show laxative effect
[6]. The extracts of P.niruri have a wide range of pharmacological activities like antimicrobial, antiviral, hepato protective, antioxidant, anticancer, antiinflammatory, antiplasmodial and diuretic[7].To the best of our knowledge and literature survey, P.niruri has not been used for the synthesis of silver nanoparticles. In this study, an attempt was made to the green synthesis of AgNPs from P.niruri and was characterized. The same was also used to assess their effect on biological systems.

\section{MATERIALS AND METHODS}

\section{Plant material extraction}

Well matured fresh, healthy Phyllanthus niruri leaves were collected from Saliyamangalam, Thanjavur district, Tamilnadu, India and authenticated by professionals in Department of Botany, St. Joseph's College, Tiruchirappalli, India. The herbarium number of the plant is BA 001.The plant materials was washed three times in tap water and two times in distilled water at room temperature during the process all dust and soils are removed and collected plants are dried at room temperature in open air, shadow dried ten days. Then $100 \mathrm{~g}$ of coarse powder was crushed dried plant 
material by using grinder, the soxhlet apparatus were used to plant extraction of $250 \mathrm{ml}$ aqueous using coarse powder and extracts was used to treat further investigation.

\section{Characterization Techniques}

\section{UV-Vis spectra analysis}

The silver nanoparticles were confirmed by measuring the wave length of reaction mixture in the UV - Vis spectrum of the PerkinElmer spectrophotometer at a resolution of $1 \mathrm{~nm}$ (from 300 to $600 \mathrm{~nm}$ ) in $2 \mathrm{ml}$ quartz cuvette with $1 \mathrm{~cm}$ path length.

\section{SEM analysis}

The morphological characterization of the samples was done using JEOL Jsm- $6480 \mathrm{LV}$ for SEM analysis. The samples were dispersed on a slide and then coated with platinum in an auto fine coater. After that the material was subjected to analysis.

\section{FT-IR analysis}

The characterization of functional groups on the surface of AgNPs by plant extracts were investigated by FTIR analysis (Shimadzu) and the spectra was scanned in the range of $4000-400 \mathrm{~cm}-1$ range at a resolution of $4 \mathrm{~cm}^{-1}$. The samples were prepared by dispersing the AgNPs uniformly in a matrix of dry $\mathrm{KBr}$, compressed to form an almost transparent disc. $\mathrm{KBr}$ was used as a standard in analysis of the samples.

\section{Anti-Bacterial Study}

Muller Hinton Agar plates were prepared and the test microorganisms A.hydrophila were inoculated by the spread plate method. Filter paper discs approximately $6 \mathrm{~mm}$ in diameter were soaked with $50 \mu \mathrm{l}$ of the plant extract, $\mathrm{AgNo}_{3}$ and $\mathrm{AgNp}_{\mathrm{s}}$ placed in the previously prepared agar plates. Each disc was pressed down to ensure complete contact with the agar surface and distributed evenly so that they are no closer than $24 \mathrm{~mm}$ from each other, center to center. The agar plates were 45 then incubated at $37^{\circ} \mathrm{C}$. After 16 to 18 hours of incubation, each plate was examined. The resulting zones of inhibition were uniformly circular with a confluent lawn of growth. The diameters of the zones of complete inhibition were measured 8 .

\section{RESULTS AND DISCUSSION}

\section{Synthesis of silver nanoparticles}

In order to synthesize silver nanoparticles (SNPs), $10 \mathrm{~mL}$ of the leaf extract was mixed with $90 \mathrm{~mL}$ of $1 \mathrm{mM}$ silver nitrate solution and heated in a water bath, set at $80^{\circ} \mathrm{C}$ for $10 \mathrm{~min}$. A color change from yellow to dark brown designates the formation of colloidal SNPs (Figure: 1) ${ }^{9}$.

\section{UV-Vis Spectra analysis:}

As shown in figure 2, the appearance of brownish color in the reaction mixture indicates the formation of AgNPs. The change in color of the solution was due to the surface plasmon resonance (SPR) and reduction of silver ions by aqueous extract of P.niruri In the present result, the Surface Plasmon Resonance (SPR) of AgNPs produced a peak at $423 \mathrm{~nm}$, which suggests the dispersal of silver nanoparticles. The SPR bands are influenced by the size, shape, morphology, composition and dielectric environment of the prepared nanoparticles ${ }^{10}$. Previous studies have shown that the spherical AgNPs contribute to the absorption bands at around $400-420 \mathrm{~nm}$ in the UV-visible spectra ${ }^{11}$. These absorption bands were assumed to correspond to the AgNP's extra-fine nature, with relatively small size.

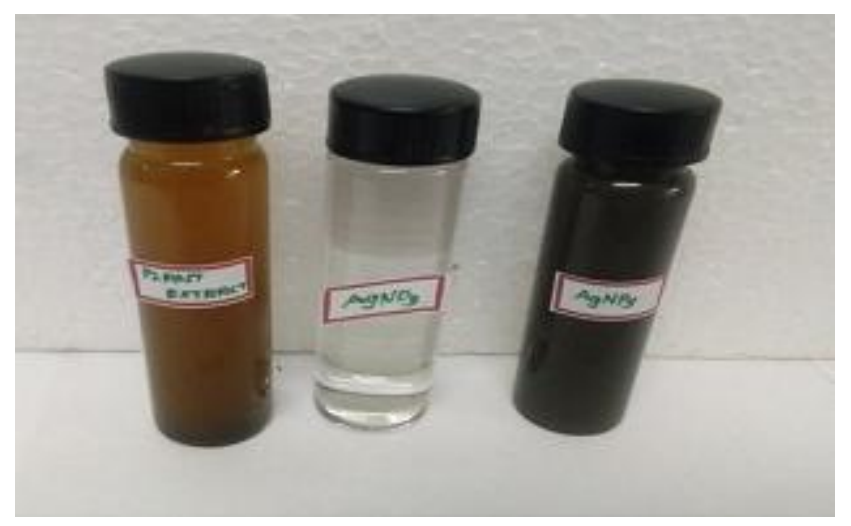

Figure 1: Silver nanoparticles visible observation

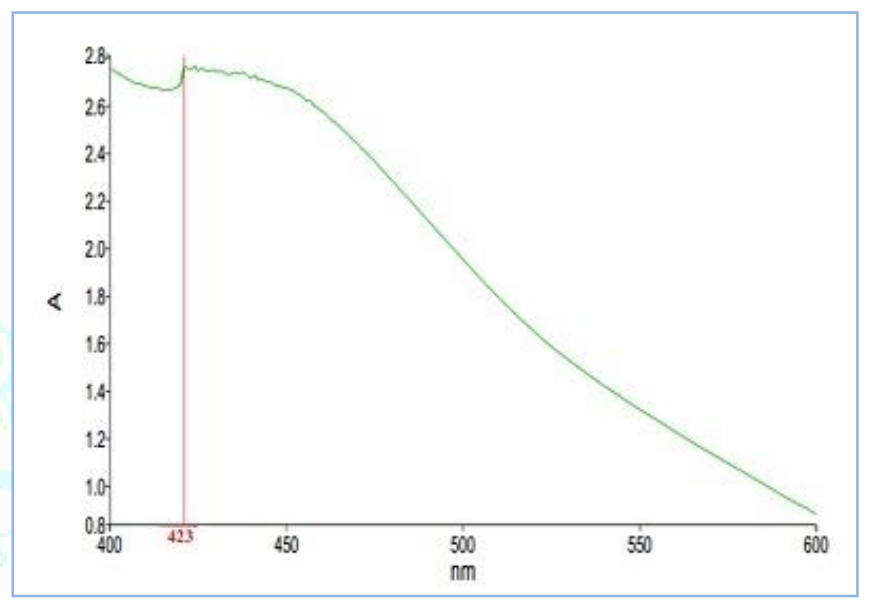

Figure 2: UV-Vis Spectroscopy for silver nanopaticles

\section{SEM analysis of silver nanoparticles}

The surface morphology and topography of the SNPs were examined by scanning electron microscopy. Figure 3. Shows high density AgNPs synthesised by the plant extract of P.niruri more confirmed the presence of AgNPs. The interactions such as hydrogen bond and electrostatic interactions between the bio-organic capping molecules bond are the reason for synthesis of silver nanoparticles using plant extract 12. Figure 3 showed that silver nanoparticles are cubical, rectangular, triangular and spherical in shape with uniform distribution. However, on most occasions, agglomeration of the particles was observed probably due to the presence of a weak capping agent which moderately stabilized the nanoparticles 13 . The measured sizes of the agglomerated nanoparticles were in the range 5$50 \mathrm{~nm}$; however, the average size of an individual particle is estimated to be $15 \mathrm{~nm}$. The larger silver particles may be due to the aggregation of the smaller ones. 


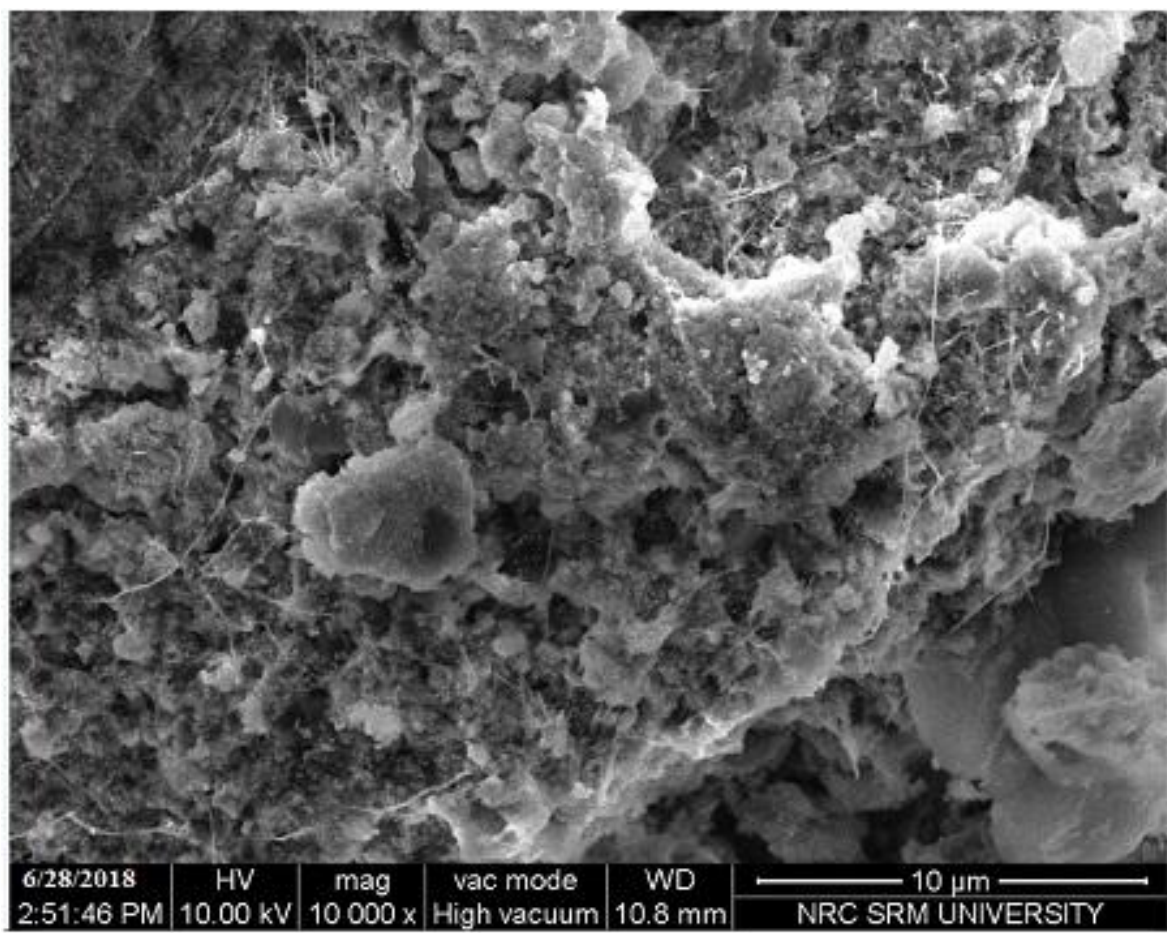

Figure 3: Scanning Electron Microscopy for silver nanopaticles

\section{FTIR analysis}

FT-IR spectra taken to detect the major functional groups in plant extract and their possible role in reduction process during the synthesis of AgNPs and stabilization of silver nanoparticles and spectrum peaks were compared with standard values to identify the main biomolecules present in the plant extract. The spectra showed absorption peaks at $3612 \mathrm{~cm}^{-1}, 3498 \mathrm{~cm}^{-1}, 2720 \mathrm{~cm}^{-1}, 1758 \mathrm{~cm}^{-1}, 1638 \mathrm{~cm}^{-1}, 910$ $\mathrm{cm}^{-1}$ and $610 \mathrm{~cm}^{-1}$. The spectra showed broad transmission peak at $3612 \mathrm{~cm}^{-1}$ and $3498 \mathrm{~cm}^{-1}$, which corresponds to hydrogen bonded hydroxyl group $(\mathrm{O}-\mathrm{H}$ and $\mathrm{H}$ stretch) of alcohols and phenols.

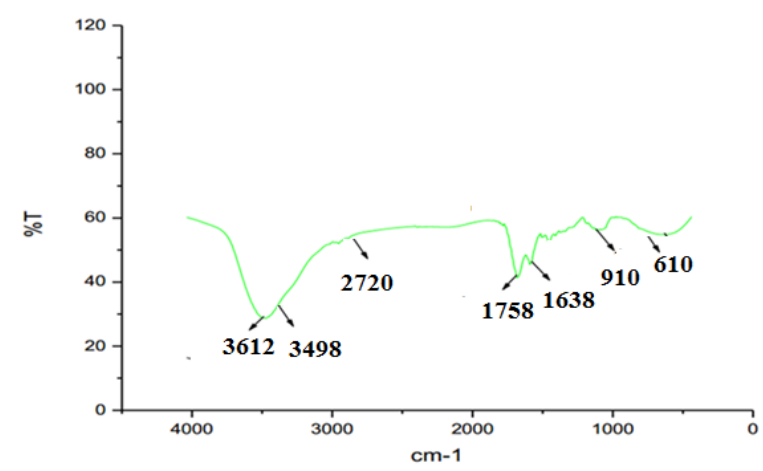

Figure 4: FTIR Analysis for silver nanopaticles

The $2720 \mathrm{~cm}^{-1}$ peak corresponds to (O-H stretch) carboxylic acids. The $1758 \mathrm{~cm}^{-1}$ peak corresponds to ( $\mathrm{C}=0$ stretch) carboxylic acids. The 1638 peak corresponds to (N-H bend) amines. The $910 \mathrm{~cm}^{-1}$ (O-H bend) carboxylic acids. The 610 peak corresponds to $(-\mathrm{C} \equiv \mathrm{C}-\mathrm{H}$ : $\mathrm{C}-\mathrm{H}$ bend) alkynes. These bands denote stretching vibrational bands responsible for compounds like flavonoids and terpenoids 14,15 and so may be held responsible for efficient capping and stabilization of obtained AgNPs. From FT-IR results, it can be concluded that some of the bioorganics compounds from P.niruri extract formed a strong coating/capping on the nanoparticles (Figure: 4).

\section{Antibacterial Assay}

Antibacterial assay of biosynthesised silver nanoparticles was studied against A.hydrophila bacteria using agar disc diffusion method and zone of inhibition is depicted in figure5 and in Table- 1 . The maximum zone of inhibition against A.hydrophila $(14 \mathrm{~mm})$ on normal plant leaves extract. The synthesized silver nanoparticles were tested against selected bacterial pathogens. The maximum zone of inhibition against A.hydrophila is $16 \mathrm{~mm}$.The silver nanoparticles showed maximum zone of inhibition against fish bacterial pathogen of A.hydrophila than normal plant extract. Silver ions as well as Ag Nps were known to have strong antimicrobial activities 16. The antibacterial activity of different solutions containing Ag Nps demonstrated that both Gram positive and Gram negative bacteria were inhibited by different solutions with different extents. The results of the antibacterial assay are depicted in Figure.5. These results agreed with previous work carried out by 17-20.

Table 1: Antibacterial activity of $\mathrm{AgNO}_{3}$, AgNPS and leaves extract of Phyllanthus niruri

\begin{tabular}{|l|c|l|}
\hline Sample & Concentrations & A.hydrophila (mm) \\
\hline $\mathrm{AgNO}_{3}$ & $50 \mu \mathrm{l}$ & $8 \pm 0.03$ \\
\hline Plant extract & $50 \mu \mathrm{l}$ & $14 \pm 0.10$ \\
\hline AgNPs & $50 \mu \mathrm{l}$ & $16 \pm 0.09$ \\
\hline
\end{tabular}

Values were expressed as Mean $\pm \mathrm{SD} . \mathrm{AgNO}_{3}=$ Silver Nitrate; AgNPs = Silver Nanoparticles 


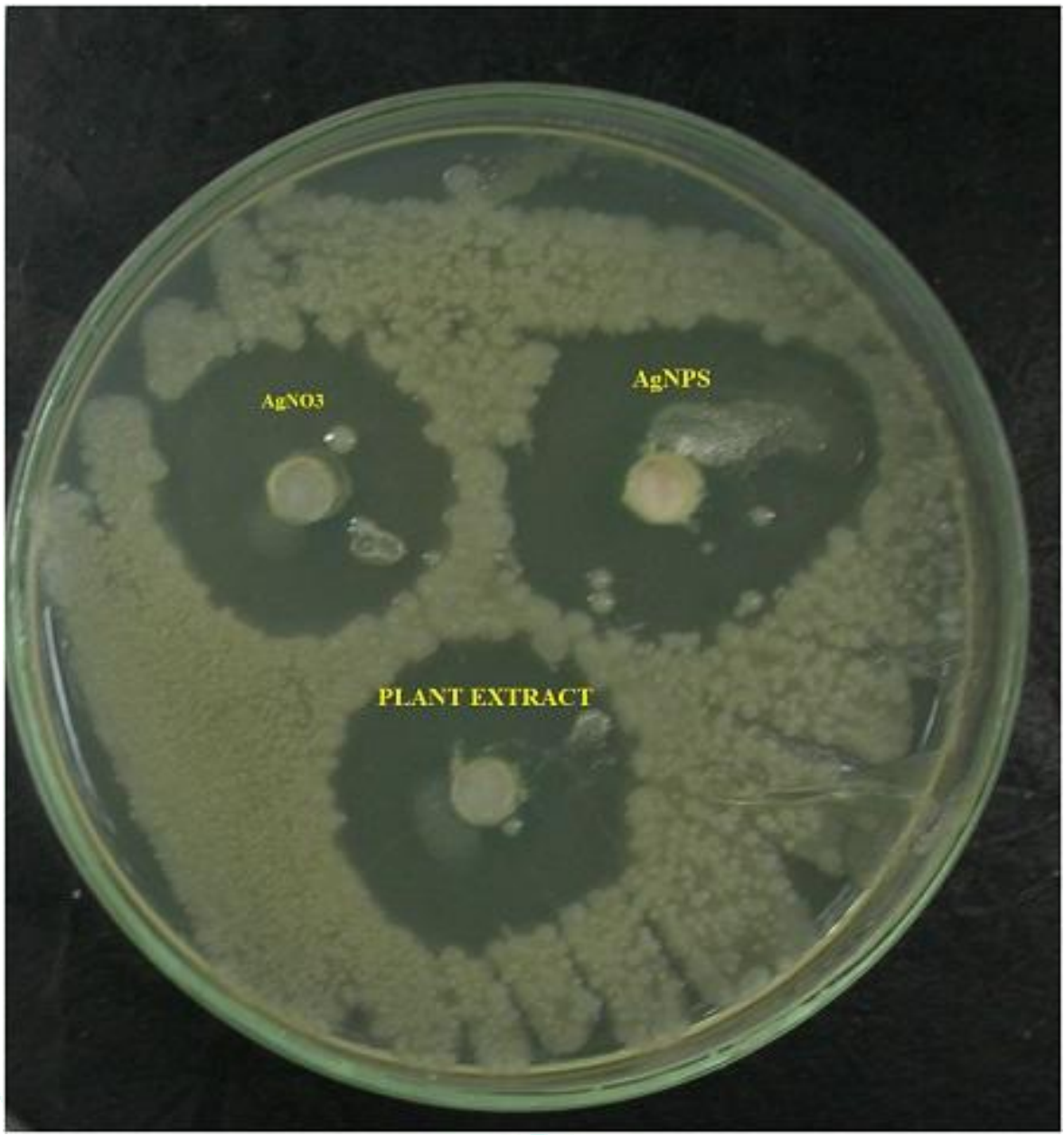

Figure 5: Antibacterial Activity

\section{CONCLUSION}

The present study showed a simple rapid and economical rout to synthesize silver nanoparticles. For synthesis of silver nanoparticles through P.niruri leaves extract can be effectively used to follow a greener rout. Control over biological synthesis provides particles with good control over size distribution and shape. P.niruri leaves extract produced silver nanoparticles have been used in various applications for human being. Further the above silver nanoparticles revealed to possess an effective antibacterial property against Aeromonas hydrophila. Silver nanoparticles synthesized via green rout were highly toxic to pathogenic bacteria, hence has a great potential in biomedical application and a potent antibacterial effect too. This green method resulted many advantages such as ecofriendly, low cost and large scale synthesis of silver nanoparticles.

\section{CONFLICT OF INTEREST STATEMENT}

We declare that we have no conflict of interest.

\section{REFERENCES}

1. Siavash Iravani: Green synthesis of metal nanoparticles using plants, Green Chem 2011; 13:2638-2650.

2. Vasanth K, Ilango K, Mohankumar R: Anticancer activity of Moringa oleifera mediated silver nanoparticles on human cervical carcinoma cells by apoptosis induction, Colloids Surf. B Biointerfaces 2014; 117:354-359.

3. Balayssac S, Trefi S, Gilard V, Malet-Martino M, Martino R, Delsuc MA: 2D and 3D DOSY 1H NMR, a useful tool for analysis of complex mixtures: application to herbal drugs or dietary supplements for erectile dysfunction. J Pharm Biomed Anal 2009; 50:602-12.

4. Thomas R, Nair AP, Kr S, and Mathew J, Ek R: Antibacterial activity and synergistic effect of biosynthesized AgNPs with antibiotics against multidrug-resistant biofilm-forming coagulase-negative staphylococci isolated from clinical samples. Appl Biochem Biotechnol 2014; 173:449-60.

5. R.Vijayaraj, K.Naresh Kumar, P.Mani, J.Senthil, G.Dinesh Kumar and T.Jayaseelan. Green Synthesis of Silver Nanoparticles from Ethanolic Seed Extract of Acranythes aspera (linn.) and its Antiinflammatory Activities. International Journal of Pharmacy \& Therapeutics 2016; 7 (1):42-48.

6. Hakim Md. Kamruzzaman and Obydul Hoq Md: A review on ethnomedicinal, phytochemical and pharmacological properties of Phyllanthus niruri. Journal of Medicinal Plants Studies 2016; 4(6):173-180.

7. Bagalkotkar G, Sagineedu SR, Saad MS, Stanslas J: Phytochemicals from Phyllanthus niruri Linn. and their pharmacological properties: a review. J Pharm. Pharmacol. 2006; 58:1559-1570.

8. National Committee for Clinical Laboratory Standards. NCCLS Document M100 - S8. Performance Standards for Antimicrobial Susceptibility Testing. 8th edition, NCCLS, Waynae, pp.1998.

9. Raja S, Ramesh V, Thivaharan V: Green biosynthesis of silver nanoparticles using Calliandra haematocephala leaf extract, their antibacterial activity and hydrogen peroxide sensing capability. Arabian Journal of Chemistry, 2017; 10:253-261.

10. Stepanov AL: Optical properties of metal nanoparticles synthesized in a polymer by ion implantation: a review. Tech. Phys 1997; 49: 143-153.

11. Shameli K, Ahmad MB, Jazayeri SD: Investigation of antibacterial properties silver nanoparticles prepared via green method. Chem. Cent. J 2012; 6:73.

12. Mano PM, Karunai SB, John PJA: Green synthesis of silver nanoparticles from the leaf extracts of Euphorbia Hirta and Nerium Indicum. Dig J Nanomater Biostruct 2011; 6(2):869877.

13. Nethra DC, Sivakumar P, Renganathan S: Green synthesis of silver nanoparticles using Datura metel flower extract and evaluation of their antimicrobial activity. Int J Nanomater Biostruct 2012; 2(2):16-21. 
14. Siddiqui BS, Afshan F, Faizi GS, Naqui SNH, Tariq RM: Two insecticidal tetranortriterpenoids from Azadirachta indica. Phytochemistry 2000; 53:371-376.

15. Huang Q, Li D, Sun Y, Lu Y, Su X, Yang H, Wang Y, Wang W, Shao $\mathrm{N}$, Hong J, Chen C: Biosynthesis of silver and gold nanoparticles by novel sundried Cinnamomum camphora leaf. Nanotechnol 2007; 18:105104

16. Furno F, Morley KS, Wong B, Sharp BL, Arnold PL, Howdle SM, Bayston R, Brown PD, Winship PD, Reid H: Silver nanoparticles and polymeric medical devices. J. Antimicrob. Chemother 2004; 54:1019-1024.

17. Kim JS, Kuk E, Yu KN, Kim JH, Park SJ, Lee HJ, Kim SH, Park YK, Park YH, Hwang CY, Kim YK, Lee YS, Jeong DH, Cho MH:
Antimicrobial effects of silver nanoparticles. Nanomed: Nanotechnol. Biol. Med 2007; 3:95-101.

18. Li WR, Xie XB, Shi QS, Zeng HY, Ou-Yang YS, Chen YB Antibacterial activity and mechanism of silver nanoparticles on Escherichia coli. Appl. Microbiol. Biotechnol 2010; 85:11151122.

19. Li WR, Xie XB, Shi QS, Duan SS, Ou-Yang YS, Chen YB: Antibacterial effect of silver nanoparticles on Staphylococcus aureus. Biometals 2011; 24:135-141.

20. Bindhu MR, Umadevi M: Synthesis of monodispersed silver nanoparticles using Hibiscus cannabinus leaf extract and its antimicrobial activity. Spectrochimica Acta Part A 2013; 101:184-190. 